\title{
1980: Paul Zumthor prend sa retraite
}

\section{Alain Corbellari}

\section{(2) OpenEdition}

Journals

Édition électronique

URL : http://journals.openedition.org/edl/2392

DOI : 10.4000/edl.2392

ISSN : 2296-5084

\section{Éditeur}

Université de Lausanne

\section{Édition imprimée}

Date de publication : 15 mars 2020

Pagination : 125-128

ISBN : 978-2-940331-73-4

ISSN : 0014-2026

\section{Référence électronique}

Alain Corbellari, « 1980: Paul Zumthor prend sa retraite », Études de lettres [En ligne], 312 | 2020, mis en ligne le 24 mars 2020, consulté le 17 septembre 2020. URL : http://journals.openedition.org/edl/2392 ; DOI : https://doi.org/10.4000/edl.2392

(c) Études de lettres 
Il est rare que la retraite d'un professeur d'université soit remarquable pour d'autres raisons que celles qui règlent le jeu - parfois frénétique de chaises musicales qui préside à la repourvue (quand repourvue il y a) de son poste. La plupart des retraités académiques, quand bien même ils se promettent d'enfin écrire ce qu'ils n'ont pas eu le temps de méditer lorsque les accaparaient les nécessités de l'enseignement, réduisent généralement leur activité scientifique, voire se cantonnent - ceci dit sans métaphore - à cultiver leur jardin.

Dans le cas du grand médiéviste suisse Paul Zumthor (1915-1995), sa retraite de l'Université de Montréal, où il enseignait depuis 1972 (après avoir été en poste à Groningue, Amsterdam, Paris-Vincennes et - très brièvement - à Yale) a cependant coïncidé avec le début de la dernière phase de sa carrière scientifique, celle qui lui a fait définitivement dépasser les cadres de sa spécialité et lui a conféré la stature d'un intellectuel de premier plan dans le domaine des études littéraires comparées. "Littéraires» n'est d'ailleurs pas vraiment le mot qui convient en l'occurrence, puisque c'est précisément à dynamiter cette appellation que Zumthor a consacré les quinze dernières années de sa vie en se faisant le chantre de l'oralité et des pratiques que l'on pourrait justement dire "para-littéraires" liées à ce médium essentiel de l'invention poétique qu'est la voix.

Tour à tour historien de la littérature dans le sens le plus classiquement lansonien du terme (Merlin le prophète, 1943), linguiste (collaborateur du Französisches Etymologisches Wörterbuch à la fin des années 1940), historien (La vie quotidienne en Hollande au temps de Rembrandt, 1957, qui est son livre le plus lu en même temps que le plus éloigné de ses 
préoccupations essentielles), formaliste (Langues et techniques poétiques à l'époque romane, 1963), structuraliste (Essai de poétique médiévale, 1972, qui reste son livre le plus célèbre chez les médiévistes), para-oulipiste (Le masque et la lumière. La poétique des grands rhétoriqueurs, 1978) et même romancier (Le puits de Babel, 1969), Zumthor, au cours d'une carrière atypique et proliférante, s'est imposé comme un des médiévistes incontournables du XXe siècle. Outre l'année de sa retraite, 1980 est aussi celle de la publication de Parler du Moyen Âge, un ouvrage partiellement autobiographique où il règle ses comptes avec ses anciens maîtres, et même avec une discipline qu'il a grandement contribué à faire sortir de l'ornière positiviste et du graphocentrisme.

Violemment opposé à "ces XVI", XVII e, XVIII e siècles qui ne furent, à bien des égards, qu'un bref épisode régressif de l'histoire occidentale», persuadé de «l'identité profonde du discours critique et de la poésie» ${ }^{1}$, Zumthor n'a en effet cessé d'opposer à l'exaltation classicisante de l'écrit et à l'assimilation bédiériste des auteurs du Moyen Âge à ceux de notre Modernité l'idée que ce qui prime, dans la littérature médiévale, c'est au contraire sa "mouvance», présence irréductible de l'oralité dans un art non encore mis en coupe réglée par l'imprimerie. Proche en cela de Charles-Albert Cingria (chantre du chant grégorien et des troubadours, qui appela toujours de ses vœux le retour à la musique "objective» d'avant le XVII e siècle) et de Marshall McLuhan (dont il ne partageait cependant pas tout à fait l'optimisme quelque peu naif), Zumthor a ainsi imposé dans l'Essai de poétique médiévale, sa vision d'un "grand chant courtois" dominé par une combinatoire mémorielle et d'un art littéraire essentiellement anonyme, idéalement en phase avec les revendications modernistes de Barthes et de Foucault, qu'il avait rencontrés dans la foulée de Mai 68 lorsqu'il enseignait à Vincennes; ces années brèves mais fécondes lui avaient fait prendre conscience de ses affinités avec le structuralisme.

Hôte régulier, dès leur création, de la revue Poétique et de la collection du même nom, il va ainsi s'acheminer vers une vision de plus en plus résolument formaliste de la pratique médiévale, susceptible, à ses yeux, d'ouvrir nos horizons sur des modes de faire destinés à dépasser les cadres rigides de la littérature moderne. Ayant été titulaire, à Montréal, d'une chaire non de lettres médiévales mais de littérature comparée,

I. Paul Zumthor, Parler du Moyen Âge, p. 58 et 102. 
il va donc pouvoir, une fois sa retraite prise, consacrer presque toutes ses dernières recherches à élargir le champ de la «littérature orale» (si l'on veut bien accepter cet oxymore), en en précisant et en en théorisant les modalités dans l'histoire comme dans la société d'aujourd'hui. Auteur de l'Introduction à la poésie orale (1983), de La lettre et la voix (1987), encore parus dans la collection "Poétique», ainsi que de La poésie et la voix dans la civilisation médiévale (1984), il a profité de son ancrage américain pour bâtir des ponts entre cultures francophone et anglophone et se trouve ainsi à l'origine de l'acclimatation en français de l'anglicisme "performance» (ce qui pour les puristes n'est certainement pas son plus haut titre de gloire...). Rien d'étonnant, donc, à ce que les "poètes sonores" d'aujourd'hui voient en lui l'un de leurs maîtres à penser, comme en témoignent sa préface au collectif Poésies sonores, édité en 1992 par Vincent Barras, et le volume Les riches heures de l'alphabet (1992 également), écrit en collaboration avec Henri Chopin.

Grand voyageur, homme de limes et de terres nouvelles (il n'a que brièvement vécu dans sa patrie, et uniquement dans les villes frontières de Genève et de Bâle), Zumthor a pu, dans ses dernières années, rencontrer en Afrique et en Amérique latine des témoins vivants des pratiques orales traditionnelles; il en a laissé le témoignage dans quelques textes, parfois nostalgiques, de son ultime recueil de nouvelles, La porte à côté (1994), consacrant en outre à La mesure du monde le dernier grand essai paru de son vivant (1993); un essai inachevé posthume paraîtra encore en 1996, prémonitoirement intitulé Babel ou l'inachèvement!

En libérant Zumthor des contraintes académiques, l'année 1980 est bien celle qui a permis l'universalisation de sa réflexion, preuve que le Moyen Âge mène à tout à condition d'en sortir!

Alain Corbellari Section de français, Faculté des lettres, Université de Lausanne

\author{
BIBLIOGRAPHIE
}

Zumthor, Paul, Parler du Moyen Âge, Paris, Minuit, 1980. 
